\title{
Teaching Resources Construction and Flipped Classroom Practice Based on "Ubiquitous Learning" Environment-Taking the Teaching of Microeconomics as an Example
}

\author{
Wei Peng, Ruyu Zhang, Yongyi Li
}

Beijing Normal University, Zhuhai

\section{Keywords: Teaching resources; U-Learning; flipped classroom; Microeconomics}

Abstract. With the development of information technology, ubiquitous learning (U-Learning) has become popular. The flipped classroom which combines the advantages of online learning and traditional face-to-face teaching, and features in individuation, flexibility and openness has become a hotspot in the reform of college teaching. This study attempts to introduce the flipped classroom teaching mode in the context of "ubiquitous learning" into the teaching design and teaching practice in the teaching of Microeconomics. Through inverting the order of knowledge transferring and mixing multiple learning activities, we try to improve the quality of teaching and develop students' lifelong learning ability. It was also expected to become a model of other courses in the reform of teaching mode.

\section{Introduction}

The rapid development of science and technology has ushered the era of big data and information. Mobile technology has brought about a new technological revolution. Intelligent mobile terminals, 4G networks, and the upcoming 5G networks and platforms like WeChat are developing rapidly, bringing unprecedented impact on and a new perspective for our lives, as well as the education sector. The popularization of computers has promoted multimedia teaching. The teaching methods are undergoing great changes. The traditional dictation, chalk writing, and paper textbooks have been partly replaced by multimedia display for sounds, images, videos, and texts. The flipped classroom aims at unblocking the closed classroom to enable learning everywhere, which has been backed in hardware by the development of mobile terminals and the services of the teaching and learning platform ${ }^{[1]}$. Moreover, the development of technology allows anyone to get the information they need at any time and place, and learning becomes ubiquitous, which lead to U-Learning. Ubiquitous learning is an ideal way of individualized learning, and it is a smart education characterized by situation ${ }^{[2]}$. It enables anyone to learn at any time, any place. In particular, the interactive features of ubiquitous learning can help students interact with experts, teachers or peers synchronously or asynchronously, making knowledge more accessible and resources be used effectively. However, as more and more technologies are applied to the learning process, a large number of learning channels and learning resources make people feel at sea. Against the backdrop of ubiquitous learning, we should not only introduce learning resources to learners, but more important to provide learners with a variety of context-based system frameworks including learning content, learning strategies, and learning activities. Is the intelligent environment universal in ubiquitous learning? What is the role of the teacher in the flipped classroom? How to grasp the degree of participation of teachers in the process of student learning? These questions are worthy of in-depth thinking by researchers.

\section{Reflection on the Traditional Class Teaching Mode of Microeconomics}

Microeconomics is a major component of modern economics. It is a professional basic theory course for students major in economics and management. It mainly studies how market allocates scare resources. The course teaching should enable students to skillfully use the knowledge they have learned to explain, analyze and predict socio-economic phenomena, and have the ability to explore and creatively solve economic problems. It is undeniable that the class teaching mode is a major advancement in the history of 
education, and has played an important role in promoting the formation of the education industry chain and the rapid development of education. However, in the information age, it has some disadvantages.

First, the form of teaching is monotonous. At present, although there are a large number of textbooks of microeconomics, but the existing teaching method is to move the electronic teaching resources onto the screen, which is not in line with the students' understanding rules and thinking pattern. Multidimensional teaching materials are not interactive and interactive and cannot satisfy students' independent learning.

Second, the 45-minute time in the classroom is limited. The way students acquire knowledge is mainly based on classroom. Generally speaking, the cyclical process of "teachers deliver, students listen and inquire" can convey most of the professional knowledge. However, the class is limited within 45 minutes. Even if the teaching case is directly provided by the teacher, the time may be insufficient for the students to fully understand the case in detail, affecting the cultivation of the students' manual dexterity.

Third, emphasizing overall teaching progress leads to neglecting individual differences. if students in the same class are taught with the same content at the same pace, differences in individual ability of students will be ignored, which violates the educational thoughts of "No Child Left Behind", and is not in harmony with the "student-centered" teaching reform in the new era.

Therefore, embedding ubiquitous learning into the flipped classroom will help to realize the lifelong learning, information learning and individualized learning ${ }^{[3]}$. The ubiquitous learning facilitates the fragmentation learning, creates a mobile classroom for us to learning what we need" and boasts situation-based resource navigation, so it is conducive to the reform of traditional classroom teaching pattern ${ }^{[4][5]}$.

\section{Ubiquitous Teaching Resources Integration in the Teaching of Microeconomics}

Ubiquitous learning requires ubiquitous networks, computing, learning resources, and learning services. The learning resources and services exist in the device in a distributed storage manner, and information is exchanged through computing and network, so that the learner obtains the desired learning materials. At present, ubiquitous learning has the following three basic characteristics. (1) Ubiquity. The fragmentation of time leads to the fragmentation of learning, learning becoming a part of life like air and water. (2) Integration. It means the multivariate and multi-directional integration of learning environment (family, school, and community), learning tools (equipment at your fingertips), and learning style (formal and informal, individual learning and group learning). (3) Situation-based. The dynamic change of the situation requires that the learner can access the corresponding resources, and the learner can participate in different situations as needed. In the ubiquitous learning, the role of a traditional teacher is weakened, and learners care more about solutions to situational problems rather than test scores. Based on this, in the process of constructing the ubiquitous learning environment of the teaching of Microeconomics, the following efforts are made:

1. Provide a wide range of learning tools. Based on the traditional pen and paper recording tools, students are encouraged to use computers and network equipment, for example, WeChat Group, WeChat official account, forum, blog, WIKI, MOOC, BBS, QQ, and intranet network social software and social networking sites and other learning tools and channels.

2. Establish a resource pool that is up to date. Specifically, massive learning resources are divided into four broad categories, namely presupposition learning resources, formative learning resources, associated learning resources, and generalized learning resources. The connotation of the four learning resources and their specific applications in the course of Series of Finance are as follows (see Table 1): 
Table 1 Learning resource pool

\begin{tabular}{|c|c|c|}
\hline Resources & Connotation & Content \\
\hline \multirow[b]{3}{*}{$\begin{array}{l}\text { presupposition } \\
\text { resources }\end{array}$} & \multirow{3}{*}{$\begin{array}{l}\text { Refers to the resources that teachers make or } \\
\text { set up beforehand and require learners to use } \\
\text { according to their learning needs and the } \\
\text { requirements for carrying out learning } \\
\text { activities. }\end{array}$} & Syllabus of Macroeconomics \\
\hline & & Microeconomics paper textbook \\
\hline & & Modular, task-oriented short video \\
\hline \multirow{2}{*}{$\begin{array}{l}\text { Formative } \\
\text { resources }\end{array}$} & \multirow{2}{*}{$\begin{array}{l}\text { Refers to the resources generated based on } \\
\text { questions, confusion, feelings, and opinions } \\
\text { of students during the teaching process. }\end{array}$} & $\begin{array}{l}\text { Learn in group the "Target Guidance" } \\
\text { which is divided into self-study, group } \\
\text { discussion and solving doubts }\end{array}$ \\
\hline & & $\begin{array}{l}\text { Case analysis report distributed to each } \\
\text { group }\end{array}$ \\
\hline \multirow{2}{*}{$\begin{array}{l}\text { Associated } \\
\text { resources }\end{array}$} & \multirow{2}{*}{$\begin{array}{l}\text { Refers to the resources centering on the } \\
\text { purpose of learning and have the scope of the } \\
\text { search }\end{array}$} & $\begin{array}{l}\text { High-quality open educational } \\
\text { resources on the Internet, such as: } \\
\text { Harvard, Yale Open Class, China } \\
\text { National Quality Course, University } \\
\text { Open Class, etc. }\end{array}$ \\
\hline & & $\begin{array}{l}\text { Course related to Microeconomics, } \\
\text { such as Management Economics, } \\
\text { Macroeconomics, Economic Analysis } \\
\text { Methods, etc. }\end{array}$ \\
\hline
\end{tabular}

\section{The Realization of Microeconomics Flipped Classroom}

In the flipped classroom of Microeconomics, we need to achieve a series of goals, such as maximizing the "preview time", "classroom time" interactive practice, and the cultivation of reflective autonomous learning ability. ${ }^{[6]}$. The performance of flipped classroom can be evaluated in the following aspects. Whether the flipped classroom teaching can be appreciated by the learners? Has the internalization and appreciation of learning knowledge been realized? Does it make students' academic performance and practical ability better compared to traditional teaching? Therefore, the focus of the assessment of students should be on the learning attitudes, processes, methods, cooperation, etc. After learning a unit of the course, teachers should organize students to self-evaluate and evaluate each other's self-learning status, and give timely evaluation to their learning processes and methods. Students' self-evaluation, mutual evaluation, and mutual evaluation between groups should occupy a large proportion in the evaluation of learning. Before the class, during and after the class, different tasks for teachers and students are formed to clarify the different learning tasks at different time points. See the picture below for details: 


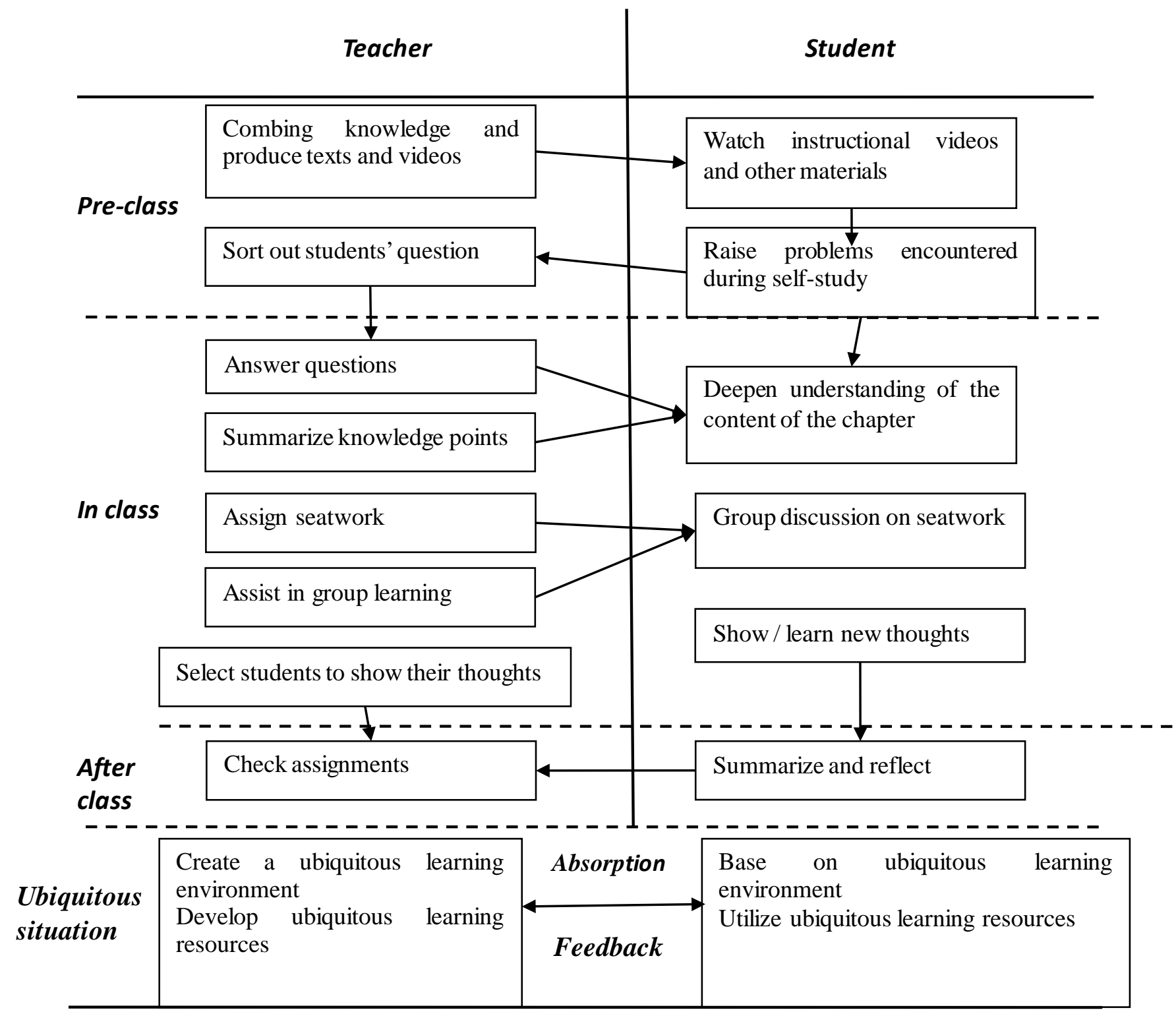

Fig.1 Teacher and student task table

In the flipped classroom teaching model of Microeconomics, we need to consider which activities are done in class, which can be done after class, which need to be done by oneself and which can be done better by grouping. Specifically, the flipped classroom is designed as an organism with "three stages, five steps and ten links".

"Three stages"- before class (self-study and raise question), during class (practice and display), after class (summary and improvement)

"Five steps" - process of teachers" lesson preparation: Integrate teaching materials $\rightarrow$ comb the "four points" (key points, difficult points, blind spots, error-prone points) $\rightarrow$ compile the case and micro-class scripts $\rightarrow$ record micro-courses $\rightarrow$ answer questions

“Ten links" - self-study stage includes five steps: "target guidance $\rightarrow$ textbook self-study $\rightarrow$ micro-class $\rightarrow$ cooperation and mutual learning $\rightarrow$ online measurement"; the practice and display stage includes three stages: "questioning and answering $\rightarrow$ practice and display $\rightarrow$ expansion and improvement"; the summary and improvement phase includes two links: "evaluation $\rightarrow$ teaching feedback”. 


\section{Conclusion}

The ubiquitous learning and flipped classroom subvert the traditional "knowledge transfer" teaching mode. Ubiquitous learning requires anyone to acquire learning resources at any time and at any place for learning. This demands both the "quantity" the "quality" of learning resources. In the process of teaching, the learning, researching, and practicing are organically combined, and students are guided to actively discover and solve problems. The construction of the ubiquitous learning resource pool of Microeconomics and the application of the Flipped Classroom in the teaching process enable students to acquire massive learning resources anytime and anywhere, internalize learning knowledge, and establish their own microeconomics knowledge network system, improve the basic literacy of problem analysis and problem solving and enhance the ability of learning in real life.

\section{Acknowledgment}

This article is funded by the following projects. Education Department of Guangdong: Design and Construction of Flipped Classroom in the Context of "Ubiquitous Learning”-Based on the Teaching Practice of Asset Evaluation(2017); Education Department of Guangdong: On the Mixed Teaching Mode of Management Courses in the Local Application-Oriented Colleges and Universities under the Combination of MOOC and "Flipped Classroom"(2016); Beijing Normal University Zhuhai Campus: Innovation Teaching Reform and Practice Based on the Three-Dimensional Two-Way Investment Course. Here expresses acknowledgement for these projects(2017).

\section{References}

[1]. Kong Shaoying, Xue Limin, Cao Li. Research and Practice of the Ubiquitous Learning Model of Modern Distance Education [J]. China Adult Education, 2018(14):7-11.(In Chinese)

[2]. Jiang Xiaoli. On the Construction of Foreign Language Independent Learning Center under the Concept of Ubiquitous Learning-Based on the Analysis of Related Researches at Home and Abroad [J]. Computer-Assisted Foreign Language Education, 2016(03):28-33. (In Chinese)

[3]. Zhao Huiqin, Zhang Tianyun, Wang Li. On the Personal Learning Space Based on Situational Perception in Ubiquitous Learning Environment [J]. China Educational Technology, 2016(07):36-42. (In Chinese)

[4]. Qin Zhiyong, Lu Wenqing. On the Deep Integration of Information Technology and Flipped Classroom in the Micro-class Era[J]. Theory and Practice of Education, 2018, 38(23):17-19. (In Chinese)

[5]. Hui Chunxiao, He Xiaoping. Visual Analysis of Flipped Classroom Research at Home and Abroad[J]. Distance Education in China, 2016(08):37-45+80. (In Chinese)

[6]. Ye Bo. Beyond Technology: Teacher's Role in the Flipped Classroom Implementation [J]. Journal of the Chinese Society of Education, 2015(08):82-85. (In Chinese) 